\title{
Clinical and psychological correlates of two domains of hopelessness in schizophrenia
}

\author{
Paul H. Lysaker, PhD; ${ }^{1-2 *}$ Michelle P. Salyers, PhD; ${ }^{3-6}$ Jack Tsai, MS; $^{1,6}$ Linda Yorkman Spurrier, MSN, RN; $^{1}$ \\ Louanne W. Davis, PsyD ${ }^{1-2}$ \\ ${ }^{1}$ Richard L. Roudebush Department of Veterans Affairs (VA) Medical Center (VAMC), Indianapolis, IN; ${ }^{2}$ Indiana Uni- \\ versity (IU) School of Medicine, Indianapolis, IN; ${ }^{3}$ VA Health Services Research and Development Center on Imple- \\ menting Evidence-Based Practice, Richard L. Roudebush VAMC, Indianapolis, IN; ${ }^{4}$ IU Center for Health Services and \\ Outcomes Research, Regenstrief Institute, Inc, Indianapolis, IN; ${ }^{5}$ ACT Center of Indiana, Indianapolis, IN; \\ ${ }^{6}$ Department of Psychology, IU-Purdue University Indianapolis, Indianapolis, IN
}

\begin{abstract}
Hopelessness is a widely observed barrier to recovery from schizophrenia spectrum disorders. Yet little is known about how clinical, social, and psychological factors independently affect hope. Additionally, the relationships that exist between these factors and different kinds of hope are unclear. To explore both issues, we correlated two aspects of hope, expectations of the future and agency, with stigma, clinical symptoms, anxiety, and coping preferences in 143 persons with a schizophrenia spectrum disorder. Multiple regressions revealed that hope for the future was predicted by lesser alienation, lesser preference for ignoring stressors, and lesser emotional discomfort and negative symptoms, accounting for $43 \%$ of the variance. A greater sense of agency was linked to lesser endorsement of mental illness stereotypes, fewer negative symptoms, lesser social phobia, and lesser preference for ignoring stressors, accounting for $44 \%$ of the variance. Implications for research and interventions are discussed.
\end{abstract}

Key words: agency, anxiety, coping, hope, negative symptoms, positive symptoms, recovery, rehabilitation, schizophrenia, social phobia, stigma.

\section{INTRODUCTION}

Hope has been identified as a key factor in recovery from mental illness [1-3]. Yet multiple reports have documented that persons with schizophrenia commonly expe- rience potent feelings of hopelessness [4-10]. They may anticipate that their needs will not be met in the future and/or have come to believe that nothing is to be gained by continuing to pursue their goals [11-12]. They may expect rejection by others and may have a pervasive sense that there is little point in persisting in the face of challenges [13-14]. These beliefs may occur as isolated thoughts or as part of a larger personal narrative in which the present and future are linked by themes of predestined ruin and resignation [15-16]. Beyond being a matter of subjective distress, hopelessness in persons with schizophrenia has been linked to persistent social and vocational dysfunction [11,17-21].

\footnotetext{
Abbreviations: BHS $=$ Beck Hopelessness Scale, ISMIS = Internalized Stigma of Mental Illness Scale, MAQ = Multidimensional Anxiety Questionnaire, PANSS = Positive and Negative Syndrome Scale, SCID = Structured Clinical Interview for the Diagnostic Statistical Manual IV, VAMC = Department of Veterans Affairs medical center, WCQ = Ways of Coping Questionnaire.

*Address all correspondence to Paul H. Lysaker, PhD; Roudebush VAMC-Psychiatry, 1481 West 10th Street, Indianapolis, IN 46202; 317-988-2546; fax: 317-554-0056. Email: plysaker@iupui.edu, paul.lysaker@med.va.gov DOI: 10.1682/JRRD.2007.07.0108
} 
To date, the research on the roots of hopelessness has consistently suggested that hopelessness may be influenced by an array of social, clinical, and psychological factors. Examining social causes of hopelessness, studies have suggested that hopelessness may result from stigma or pervasive stereotypic beliefs about severe mental illness [14,22-23]. As persons encounter and accept stigma, the possibility of future fulfillment may seem increasingly remote. At the clinical level, hope has been suggested to be influenced by positive and negative symptoms and depression [24-28]. Experiencing symptoms has been suggested to be naturally demoralizing and leads to fewer positive expectations for the future. At the psychological level, lack of hope has been linked with a generally avoidant coping style and a vulnerability to feeling anxious when facing social situations or other stressors [26,29-30]. Implied here is that as persons unsuccessfully cope with stressors, they may begin to anticipate failure, increasingly fear embarrassment, and see fewer reasons to persevere.

Although this literature highlights several barriers to hope in schizophrenia, at least two important issues remain unanswered. First, are social, clinical, and psychological factors independently related to hope? Do, for instance, stigma, coping preference, and depressed mood each uniquely contribute to the loss of hope or is there merely a general association between these phenomena? Answers to these questions may have clinical and theoretical import by pointing to discrete chains of cognition and behavior that culminate in hopelessness and that could represent independent targets for intervention. To date, at least one study has suggested that depression, stigma, and overall symptomatology independently contribute to hopelessness [31], but further examination is needed to clarify whether these contributions are independent of one another.

A second issue involves the question of whether different kinds of hope are related in a similar or dissimilar manner to social, clinical, and psychological factors. While hope is often considered a singular phenomenon, it is composed of numerous semi-independent domains or dimensions [26,32-33]. Seen through the lens of hope theory, believing that one is on the path to meeting desired goals is not necessarily the same thing as believing that one's actions will directly lead to a desired outcome [34]. As a practical example, to have hope of receiving a good work evaluation from a supervisor is not necessarily the same thing as to have hope that one can persist at work despite criticism from one's supervisor. Theoretically then, one could have one form of hope but lack the other, and perhaps, the absence of different forms of hope are linked with different outcomes. Evidence that relatively independent domains of hope exist includes findings that changes in expectations of the future and agency are linked with different variables in psychotherapy among persons without psychosis [35]. Literature suggesting that this issue is particularly relevant for persons with schizophrenia includes findings that many with schizophrenia have unique difficulties situating themselves as active agents within their own lives [36-37] and seeing promise in their future [10-11]. In schizophrenia, hope for a good outcome and hoping to persist have also been linked with different rehabilitation outcomes [17].

In the current study, we have therefore examined the relative associations of these two components of hopeexpectations of the future and agency-with multiple clinical, social, and psychological factors. The factors we selected were three forms of clinical symptoms: positive, negative, and depressive symptoms; three dimensions of stigma: discrimination experiences, alienation, and stereotype endorsement; preference for two forms of avoidant coping: ignoring and resigning; and three dimensions of anxiety: physiological-panic, social phobia, and general worries and fears. We chose these variables given their associations with hope in prior studies and also because intuitively we reasoned that symptoms, stigma, coping, and anxiety might be semi-independently linked to hope. Imaginable, for instance, is that the correlation that stigma has with hope might be partially unrelated to the correlation that negative symptoms, avoidant coping, or social anxiety have with hope. While we considered our analyses to be largely exploratory, we did make three initial sets of predictions. First, we predicted that both domains of hope would be more strongly linked to stigma than other clinical or psychological factors. We reasoned that of all the constructs measured, stigma might be the most demoralizing given its direct impact on a person's sense of his or her chances of having a fulfilling life $[14,23]$. Second, we predicted that the two different domains of hope would be related to different clinical symptoms. Here we anticipated that positive and negative symptoms would be more closely linked to lower levels of agency, since these symptoms can be closely related to the experience of one's own life as beyond one's control (e.g., as in persecutory delusions of lack of affect or volition). We anticipated that future expectations would be more closely linked to 
depression as noted by Landeen and colleagues [31]. Third, we predicted that stigma, symptoms, coping, and anxiety would be independently linked to hope. Here we reasoned that more profound levels of hopelessness might result from the additive effects of all these factors. In other words, while the experience of stigma should result in some degree of hopelessness, stigma coupled with more severe symptoms, anxiety, and an avoidant coping style would result in even higher levels of hopelessness.

\section{METHODS}

\section{Participants}

We recruited 143 participants with diagnoses of schizophrenia $(n=88)$ or schizoaffective disorder $(n=$ 55), confirmed by the Structured Clinical Interview for the Diagnostic Statistical Manual IV (SCID) [38], from the outpatient psychiatry clinic of a Department of Veterans Affairs medical center (VAMC) $(n=104)$ or a community mental health center $(n=39)$ for one of two studies: the correlates of anxiety in schizophrenia or the effects of cognitive therapy on rehabilitation outcome. All participants were in a stable or postacute phase of their disorder, as defined by participation in outpatient treatment with no hospitalizations or changes in housing or psychotropic medication within the last month. Exclusion criteria for this study included evidence of organic brain syndrome or mental retardation in a participant's chart or during an interview. On average (mean \pm standard deviation), participants were $46.77 \pm 9.62$ years old; had $12.60 \pm 2.05$ years of education; and had $12.76 \pm$ 14.94 psychiatric hospitalizations, with the first occurring at age $26.12 \pm 9.89$. Sixty-two were Caucasian (43.0\%), seventy-eight African American (54.5\%), two Latino (1.0\%), and one Native American (0.5\%). One hundred and twenty-four (92.0\%) were male, and nineteen were female (8.0\%).

\section{Instruments}

\section{Positive and Negative Syndrome Scale}

The Positive and Negative Syndrome Scale (PANSS) is a 30-item rating scale completed by clinically trained research staff after a chart review and semistructured interview [39]. For this study, we used factor-analytically derived positive, negative, and emotional discomfort components of the PANSS [40]. The emotional discomfort component is an index of distress and includes items that assess depressed mood, anxiety, guilt, and the active avoidance of others. Evidence supporting the use of factoranalytic solutions for the PANSS has been reported by numerous other investigators [41]. Interrater reliability as assessed for raters in this study found good to excellent intraclass correlations on all scale scores, with intraclass correlations ranging from 0.80 to 0.93 . To reduce the overall number of correlations produced in this study, we did not examine the cognitive or excitement components because of a lack of predictions regarding the association of these factors with hope.

\section{Internalized Stigma of Mental Illness Scale}

The Internalized Stigma of Mental Illness Scale (ISMIS) is a 29-item questionnaire that assesses subjective experience of stigma [42-43]. It presents participants with first-person statements related to having a mental illness and asks them to rate on a 4-point Likert scale how much they agree or disagree with the statements. Items are summed to provide the following subscales: alienation, which reflects feeling devalued as a member of society; stereotype endorsement, which reflects agreement with negative stereotypes of mental illness; discrimination experience, which reflects current mistreatment attributed to the biases of others; and social withdrawal, which reflects avoidance of others because of mental illness. An additional fifth score, stigma resistance, asks about participants' perceived ability to deflect stigma. Subscale scores are calculated as averages, with higher scores suggesting graver experiences of stigma. Evidence of acceptable internal consistency, test-retest reliability, and factorial and convergent validity has been reported and includes links with morale and well-being [42-43]. The instrument was presented to participants in its written form, with research assistants available to assist if participants were confused about the meaning of any item. To reduce the overall number of correlations that were produced, we considered the first three stigma subscales only, given these subscales seemed most conceptually relevant for the construct of hope.

\section{Multidimensional Anxiety Questionnaire}

The Multidimensional Anxiety Questionnaire (MAQ) is a 40-item self-report questionnaire that taps multiple domains of the experience of anxiety [44]. For this study, we were interested in three of the four subscales: physiological-panic, which assesses physiological 
symptoms of anxiety and the anticipation of panic; social phobia, which assesses worries about social embarrassment and social avoidance; and worry-fears, which assesses general experiences of worry and fearfulness in daily life. Reynolds presents evidence of acceptable internal consistency and test-retest reliability from both a general psychiatric sample and a community sample and factorial validity from a combined psychiatric and community sample [44]. The fourth subscale, negative affectivity, was not considered in order to reduce the overall number of correlations produced and because items in the subscale often involve expectations of the future and, thus, are not entirely conceptually distinct from the hope constructs being measured.

\section{Beck Hopelessness Scale}

The Beck Hopelessness Scale (BHS) is a questionnaire that asks participants to endorse statements as true or false as applied to them [32]. In this study, we used two scale scores developed by the scales' authors: expectations of the future, which taps beliefs about how much success versus frustration lies ahead in the future (e.g., “Things just won't work out the way I want them to.”), and motivational hope, which taps expectations of whether one will make an effort to influence one's life (e.g., “I might as well give up because I can't make things better for myself.”). We considered the construct of motivational hope as equivalent to agency because it essentially involves a sense that the person can meaningfully affect his or her future and, thus, we refer to this scale as measuring agency throughout this article. The BHS has been used successfully with a wide range of psychiatric, medical, and community populations [4546]. Scales of the BHS include items that reflect both hope and hopelessness and were scored such that higher scores reflect greater levels of hope.

\section{Ways of Coping Questionnaire}

The Ways of Coping Questionnaire (WCQ) is a selfreport instrument that asks participants to recall a recent stressor and then rate how often they used 66 different behaviors to cope with that particular stressor [47]. Because the factor structure of the scale may not accurately reflect coping behaviors used by individuals with chronic psychiatric illness [48], we used a rational scoring system developed to be sensitive to coping difficulties particular to severe mental illness [49]. This scoring scheme yields scores for six modes of coping: ignoring, resigning, acting, considering, positively reappraising, and self-soothing. To reduce the overall number of correlations produced, we considered only the two scales most closely linked to avoidance of problem solving: ignoring and resigning. Ignoring refers to putting the stressor out of one's mind, or choosing to "not think" about it. Resigning refers to a choice to not act because it is perceived that nothing is to be done. In one study that compared results derived from the original scoring system with our revised scoring scheme across two previous samples, the rationally devised scales had better internal consistency and predicted psychosocial function prospectively [49]. In calculating scores, we used relative scores, as we have elsewhere [49]. We obtained these scores for each scale by dividing the mean score for that scale by the mean score for the total test. This method has the advantage of pointing to participants' relative preferences and corrects somewhat for response bias.

\section{Procedures}

The research review committees of Indiana University and the Roudebush VAMC approved all procedures. After participants gave informed consent, a clinical psychologist used the SCID to determine diagnoses. After the SCID, participants in both studies were administered the PANSS interview, ISMIS, WCQ, MAQ, and BHS. A research assistant was available to assist participants if they had difficulties reading or understanding the questionnaires. PANSS ratings were performed blind to responses to the ISMIS, WCQ, MAQ, and BHS. Trained research assistants with a minimum of a bachelor's degree in a psychology-related field conducted the PANSS interviews. We did not perform interventions in either study before obtaining the baseline information analyzed here.

\section{Analyses}

Analyses were planned in four stages. First, as noted in the "Instruments" section, we selected a priori the subscales of each instrument most relevant to coping to reduce the overall number of correlations produced. This resulted in the selection of 11 from a possible 20 total variables. Second, we examined whether hope scores were linked to demographic variables. Third, we examined correlations between the two hope scores and the 11 predictor variables previously described. Given the number of correlations used [22], we reduced alpha to 0.01 and chose to use two-tailed tests despite unidirectional hypotheses. Fourth, we performed two stepwise multiple 
regressions in which variables with significant univariate correlations were allowed to enter to predict each of the hope scores.

\section{RESULTS}

Hope scores were unrelated to age, sex, education, or diagnosis (schizophrenia vs schizoaffective disorder). Both BHS hope scores were significantly correlated with each other $(r=0.68, p<0.001)$. Mean scores for the two hope subscales and the other selected measures are reported in Table 1.

To determine whether hope domains were linked with stigma, coping, anxiety, symptoms, and neurocognition, we calculated Pearson correlations. As shown in Table 2, both aspects of hope were significantly correlated with all measures. Finally, to determine whether these correlates were uniquely linked with both domains of hope, we conducted two stepwise multiple regressions, allowing all the variables to enter into the equation. As summarized in Table 3, these analyses revealed that greater hope for the

Table 1.

Hope, neurocognition, symptoms, stigma, and coping scores in participants with schizophrenia spectrum disorder $(n=143)$.

\begin{tabular}{lc}
\hline \multicolumn{1}{c}{ Measure } & $\begin{array}{c}\text { Mean } \pm \text { Standard } \\
\text { Deviation }\end{array}$ \\
\hline BHS & $5.93 \pm 2.49$ \\
Motivational Hope & $2.58 \pm 1.56$ \\
Expectations of the Future & \\
PANSS & $15.80 \pm 5.01$ \\
Positive Component & $18.55 \pm 5.23$ \\
Negative Component & $12.77 \pm 4.38$ \\
Emotional Discomfort Component & \\
ISMIS & $2.39 \pm 0.70$ \\
Alienation & $1.97 \pm 0.51$ \\
Stereotype Endorsement & $2.41 \pm 0.66$ \\
Discrimination Experience & \\
MAQ & $72.48 \pm 23.46$ \\
Physiological-Panic T-Score & $66.84 \pm 16.29$ \\
Social Phobia T-Score & $76.79 \pm 21.53$ \\
Worry-Fears T-Score & \\
WCQ & $1.00 \pm 0.35$ \\
Resigning & $0.86 \pm 0.30$ \\
Ignoring & \\
\hline BHS = Beck Hopelessness Scale, ISMIS = Internalized Stigma of Mental III- \\
ness Scale, MAQ = Multidimensional Anxiety Questionnaire, PANSS = Posi- \\
tive and Negative Syndrome Scale, WCQ = Ways of Coping Questionnaire. \\
\hline \hline
\end{tabular}

future was predicted by lesser levels of alienation, lesser coping preference for ignoring, lesser emotional discomfort, and lesser negative symptoms, accounting for 43 percent of the variance. Greater agency was linked to lesser stereotyped beliefs about mental illness, lesser negative symptoms, lesser social phobia, and lesser coping preference for ignoring, accounting for 44 percent of the variance.

\section{DISCUSSION}

Results are largely consistent with the results of previous studies of the correlates of hope [22-26,29-31]. Both the expectation of success in the future and the expectation of being able to persist were linked to lesser levels of stigma, fewer symptoms, lesser anxiety, and lesser preference for avoidant forms of coping. Partially consistent with our first prediction, several of the stigma scores were strongly correlated with both hope dimensions. When entered into a multiple regression, alienation was the most closely linked variable to expectations of the future and stereotyped endorsement was the most

Table 2.

Correlations of two hope domains with neurocognition, symptoms, stigma, and coping in participants with schizophrenia spectrum disor$\operatorname{der}(n=143)$.

\begin{tabular}{lcc}
\hline \multicolumn{1}{c}{ Correlate } & $\begin{array}{c}\text { Expectations } \\
\text { of the Future }\end{array}$ & Agency \\
\hline PANSS & $-0.28^{*}$ & $-0.26^{*}$ \\
Positive Component & $-0.30^{\dagger}$ & $-0.41^{\dagger}$ \\
Negative Component & $-0.46^{\dagger}$ & $-0.31^{\dagger}$ \\
Emotional Discomfort Component & \\
ISMIS & $-0.51^{\dagger}$ & $-0.44^{\dagger}$ \\
Alienation & $-0.43^{\dagger}$ & $-0.47^{\dagger}$ \\
Stereotype Endorsement & $-0.32^{\dagger}$ & $-0.28^{*}$ \\
Discrimination Experience & $-0.30^{\dagger}$ & $-0.34^{\dagger}$ \\
MAQ & $-0.44^{\dagger}$ & $-0.42^{\dagger}$ \\
Physiological-Panic & $-0.37^{\dagger}$ & $-0.40^{\dagger}$ \\
Social Phobia & & \\
Worry-Fears & $-0.32^{\dagger}$ & $-0.34^{\dagger}$ \\
WCQ & $-0.33^{\dagger}$ & $-0.33^{\dagger}$ \\
Resigning & \\
Ignoring & & \\
\hline${ }^{*} p<0.01$. & & \\
${ }^{\dagger} p<0.001$. & & \\
ISMIS = Internalized Stigma of Mental Illness Scale, MAQ $=$ Multidimen- \\
sional Anxiety Questionnaire, PANSS = Positive and Negative Syndrome \\
Scale, WCQ = Ways of Coping Questionnaire. \\
\hline \hline
\end{tabular}


JRRD, Volume 45, Number 6, 2008

Table 3.

Multiple regressions predicting two hope domains ( $n=143)$.

\begin{tabular}{|c|c|c|c|c|}
\hline Hope $R^{2}$ Component & Contributing Factors & $F(d f)$ & Partial $R^{2}$ & Model \\
\hline \multirow{4}{*}{ Expectations of the Future } & Alienation & $25.78(138,4)^{*}$ & $0.26^{\dagger}$ & 0.26 \\
\hline & Ignoring & & $0.07^{*}$ & 0.33 \\
\hline & Emotional discomfort & & $0.06^{*}$ & 0.39 \\
\hline & Negative symptoms & & $0.04^{\ddagger}$ & 0.43 \\
\hline \multirow[t]{4}{*}{ Agency } & Stereotyped beliefs & $26.97(138,4)^{*}$ & $0.22^{\dagger}$ & 0.22 \\
\hline & Negative symptoms & & $0.09^{*}$ & 0.31 \\
\hline & Social phobia & & $0.08^{*}$ & 0.40 \\
\hline & Ignoring & & $0.05^{*}$ & 0.44 \\
\hline
\end{tabular}

closely linked variable to agency. Partially consistent with our second prediction, different clinical symptoms had different relationships with hope. When entered into a multiple regression, negative symptoms were more closely linked to agency, while emotional distress was more closely linked to expectations of the future. Positive symptoms, however, were only modestly linked to both hope dimensions in univariate correlations.

Our third prediction was also partially supported. Stigma, symptoms, anxiety, and coping were all uniquely linked in multiple regressions to agency, while stigma, symptoms, and coping were uniquely linked to expectations of the future. Participants with greater hope for the future tended to feel more similarities between themselves and others, to have a lesser preference for ignoring in the face of stressors, and less severe emotional discomfort and negative symptoms. Participants who believed they could more greatly affect their futures tended to disagree with stereotyped portrayals of persons with mental illness, have fewer negative symptoms, have a lesser fear of social embarrassment, and have a lesser preference for ignoring challenges.

While the cross-sectional design and exploratory nature of this study do not allow us to directly address the question of causality, the results could suggest several hypotheses. Different aspects of stigma are possibly linked to different domains of hope. A sense of oneself as fundamentally similar to others may be necessary to sustain the hope that one can attain what others can in the future. The rejection of stereotyped beliefs about mental illness may be necessary to see persistence in the face of challenge as meaningful. Similarly, negative symptoms may be a strong barrier to the experience of agency. With decreased affect and interest, some may experience themselves as less than fully fledged participants in their own lives. As noted, though, these interpretations should be treated as speculative and rival hypotheses cannot be ruled out. Lower levels of hope possibly make persons more susceptible to the effects of stigma or lead to symptom exacerbation. The associations noted here may also have resulted from factors not assessed in this study. Longitudinal studies including multiple assessments of these variables are required before we will be able to tease out causal influences.

Regarding interventions, with replication, this study may suggest the importance of developing and linking services that combat stigma and address coping style, social anxiety, depression, and negative symptoms. Treatment that is multilayered and offers different interventions depending on the presence or absence of different forms of hope may also be important. For instance, persons who struggle to see themselves as able to persist may have relatively greater needs to reject stereotypes and cope with negative symptoms and social phobia. Persons who see the future as having little promise may need help managing depression and seeing themselves as belonging in their communities. These possibilities are consistent with emerging models of how psychotherapy and rehabilitation may enhance a sense of personhood and agency, thereby empowering persons to make healthier decisions about their lives [50-51].

As noted previously, several unexpected results were found that may also suggest speculation for future study. The relatively weak relationships between positive symp- 
toms and hope, for instance, may suggest that the experiences of hallucinations and delusions, while disruptive in the moment, have a limited affect on persons' expectations of their future and ability to persist over time. The modest link between discrimination experiences and hope may suggest that beyond encountering actual discrimination, the meaning that persons assign to stigma is what affects hope.

We should note that agency and expectations of the future were strongly correlated and both dimensions of hope demonstrated a pattern of similar correlations with many other measures. Thus, how these dimensions differ from each another and how they converge conceptually and empirically remain unclear. Future work is needed, including confirmatory factor analyses to empirically demonstrate the presence of these separate factors in the BHS and to confirm that the results of the multiple regression analyses we have reported were based on actual discrimination across factors.

Finally, this study had several other limitations. Participants were predominantly male and generally in their 40s. We assessed hope by using one self-report measure. Replication and more systematic study is needed with samples that include more females and males in earlier phases of illness and that incorporate multiple methods of assessing hope from the perspective of participants, their families, and practitioners. Additionally, this exploratory study represents a beginning. Many possible correlates of hope were not examined (e.g., social network) and need to be included in future studies. Given that multiple analyses were performed and that the observed correlations were modest, the clinical significance of these findings remains to be determined. Lastly, because all participants had schizophrenia spectrum disorders, we cannot determine whether the purported relationships are specific to schizophrenia. Future studies are needed that include samples of people who do not have schizophrenia in order to develop insight into whether what was found here is unique among persons who experience this illness.

\section{CONCLUSIONS}

Results suggest that the experience of stigma, negative symptoms, emotional discomfort, anxiety, and coping preferences are, to some degree, uniquely linked with hope among participants with schizophrenia spectrum disorders. The dimension of hope that involves anticipat- ing that one's goals will be attained in the future was most closely predicted by alienation due to stigma, preference for ignoring stressors, emotional discomfort, and negative symptoms. The domain of hope that was linked to a sense that one can affect one's future was most closely linked with the acceptance of stereotyped beliefs about mental illness, severity of negative symptoms, degree of social phobia, and preference for ignoring stressors.

\section{ACKNOWLEDGMENTS}

This material was based on work supported in part by the VA Rehabilitation Research and Development Service (project 828-RA).

The authors have declared that no competing interests exist.

\section{REFERENCES}

1. Deegan PE. Recovery and the conspiracy of hope. In: Proceedings of the 6th Annual Mental Health Services Conference of Australia and New Zealand; 1996 Sep; Brisbane, Australia.

2. Noordsy DL, Torrey WC, Mueser KT, Mead S, O’Keefe CD, Fox L. Recovery from severe mental illness: An interpersonal and functional outcome definition. Int Rev Psychiatry. 2002;14:318-26.

3. Salyers MP, Macy VR. Recovery-oriented evidence-based practices: A commentary. Community Ment Health J. 2005; 41(1):101-3. [PMID: 15932057$]$

4. Bassman R. Agent, not objects: Our fight to be. J Clin Psychol. 2000;56(11):1395-1411. [PMID: 11098864]

5. Bengtsson-Tops A, Hansen L. Clinical and social needs of schizophrenic outpatients living in the community: The relationship between needs and subjective quality of life. Soc Psychiatry Psychiatr Epidemiol. 1999;34(10):513-18. [PMID: 10591810]

6. Brekke JS, Long JD. Community-based psychosocial rehabilitation and prospective change in functional, clinical, and subjective experience variables in schizophrenia. Schizophr Bull. 2000;26(3):667-80. [PMID: 10993405]

7. Frese FJ. Twelve aspects of coping for persons with schizophrenia. Innov Res. 1993;2(3):39-46.

8. Hays JR, Buckle KE. Self-efficacy among hospitalized mentally ill patients. Psychol Rep. 1992;70(1):57-58.

[PMID: 1565745]

9. Moranville JT, Zisook S. Depressive symptoms in schizophrenic outpatients. Ann Clin Psychiatry. 1990;2(3):205-10. 
10. Rooske O, Birchwood M. Loss, humiliation and entrapment as appraisal of schizophrenic illness: A prospective study of depressed and non-depressed patients. Br J Clin Psychol. 1998;37(Pt 3):259-68. [PMID: 9874588]

11. Hoffman H, Kupper Z, Kunz B. Hopelessness and its impact on rehabilitation outcome in schizophrenia-An exploratory study. Schizophr Res. 2000;43(2-3):147-58. [PMID: 10858633]

12. Lecomte T, Cyr M, Lesage AD, Wilde J, Leclerc C, Ricard $\mathrm{N}$. Efficacy of a self-esteem module in the empowerment of individuals with schizophrenia. J Nerv Ment Dis. 1999; 187(7):406-13. [PMID: 10426460]

13. Roe D. A prospective study on the relationship between self-esteem and functioning during the first year after being hospitalized for psychosis. J Nerv Ment Dis. 2003;191(1): 45-49. [PMID: 12544599]

14. Wright ER, Gronfein WP, Owens TJ. Deinstitutionalization, social rejection, and the self-esteem of former mental patients. J Health Soc Behav. 2000;41(1):68-90. [PMID: 10750323]

15. Lysaker PH, France CM. Psychotherapy as an element in supported employment for persons with severe and persistent mental illness. Psychiatry. 1999;62(3):209-21.

[PMID: 10612113]

16. Kruger A. Schizophrenia: Recovery and hope. Psychiatr Rehabil J. 2000;24(1):29-37.

17. Davis LW, Nees MA, Hunter NL, Lysaker PH. Hopelessness as a predictor of work functioning among patients with schizophrenia. Psychiatr Serv. 2004;55(4):434-36. [PMID: 15067157]

18. Strauss JS. Chronicity: Causes, prevention and treatment. Psychiatr Ann. 1980;10:328-32.

19. Renegold M, Sherman MF, Fenzel M. Getting back to work: Self-efficacy as a predictor of employment outcome. Psychiatr Rehabil J. 1999;22(4):361-67.

20. Van Dongen CJ. Self-esteem among persons with severe mental illness. Issues Ment Health Nurs. 1998;19(1):29-40. [PMID: 9479100]

21. Wing JK, Brown GW. Institutionalization and schizophrenia. London (England): Cambridge University Press; 1970.

22. Markowitz FE. The effects of stigma on the psychological well-being and life satisfaction of persons with mental illness. J Health Soc Behav. 1998;39(4):335-47. [PMID: 9919855]

23. Mechanic D, McAlpine D, Rosenfield S, Davis D. Effects of illness attribution and depression on the quality of life among persons with serious mental illness. Soc Sci Med. 1994;39(2):155-64. [PMID: 8066494]

24. Awad AG, Vorunganti LN, Heslegrave RJ. A conceptual model of quality of life in schizophrenia: Description of preliminary clinical validation. Qual Life Res. 1997;6(1): 21-26. [PMID: 9062438]
25. Bradshaw W, Brekke JS. Subjective experience in schizophrenia: Factors influencing self-esteem, satisfaction with life, and subjective distress. Am J Orthopsychiatry. 1999; 69(2):254-60. [PMID: 10234391]

26. Lysaker PH, Davis LW, Hunter NL. Neurocognitive, social and clinical correlates of two domains of hopelessness in schizophrenia. Schizophr Res. 2004;70(2-3):277-85. [PMID: 15329303]

27. Norman RM, Malla AK. Correlations over time between dysphoric mood and symptomatology in schizophrenia. Compr Psychiatry. 1994;35(1):34-38. [PMID: 8149727]

28. Ventura J, Neuchterlein KH, Subotnik KL, Gitlin MJ, Sharou J. How are self-efficacy, neurocognition, and negative symptoms related to coping responses in schizophrenia? Schizophr Res. 1999;36(1):186-87.

29. Lysaker PH, Clements CA, Wright DE, Evans J, Marks KA. Neurocognitive correlates of helplessness, hopelessness, and well-being in schizophrenia. J Nerv Ment Dis. 2001;189(7):457-62. [PMID: 11504323]

30. Lysaker PH, Davis LW, Lightfoot J, Hunter N, Stasburger A. Association of neurocognition, anxiety, positive and negative symptoms with coping preference in schizophrenia spectrum disorders. Schizophr Res. 2005;80(2-3):163-71. [PMID: 16125370]

31. Landeen JL, Seeman MV, Goering P, Streiner D. Schizophrenia: Effects of perceived stigma on two dimensions of recovery. Clin Schizophr. 2007;1(1):64-68.

32. Beck AT, Weissman A, Lester D, Trexler L. The measurement of pessimism: The hopelessness scale. J Consult Clin Psychol. 1974;42(6):861-65. [PMID: 4436473]

33. Snyder CR. Reality negotiation: From excuses to hope and beyond. J Soc Clin Psychol. 1989;8(2):130-57.

34. Snyder CR, Lehman KA, Kluck B, Monsson Y. Hope for rehabilitation and vice versa. Rehabil Psychol. 2006;51(2): 89-112.

35. Irvin LM, Snyder CR, Cheavens J, Gravel L, Hanke J, Hilberg $\mathrm{P}$, Nelson N. The relationships between hope and outcomes at the pretreatment, beginning, and later phases of psychotherapy. J Psychother Integrat. 2004;14(4):419-43.

36. Holma J, Aaltonen J. The sense of agency and the search for narrative in acute psychosis. Contemp Fam Ther. 1997; 19:463-77.

37. Lysaker PH, Lancaster RS, Lysaker JT. Narrative transformation as an outcome in the psychotherapy of schizophrenia. Psychol Psychother. 2003;76(Pt 3);285-99. [PMID: 14577894]

38. Spitzer RL, Williams JB, Gibbon M, First M. Structured clinical interview for DSM-IV. New York (NY): Biometrics Research Department; 1994.

39. Kay SR, Fiszbein A, Opler LA. The positive and negative syndrome scale (PANSS) for schizophrenia. Schizophr Bull. 1987;13(2):261-76. [PMID: 3616518] 
40. Bell MD, Lysaker PH, Beam-Goulet JL, Milstein RM, Lindenmayer JP. Five-component model of schizophrenia: Assessing the factorial invariance of the positive and negative syndrome scale. Psychiatry Res. 1994;52(3):295-303. [PMID: 7991723]

41. Lindenmayer JP, Bernstein-Hyman R, Grochowski S. Fivefactor model of schizophrenia: Initial validation. J Nerv Ment Dis. 1994;182(11):631-38. [PMID: 7964671]

42. Ritsher JB, Otilingam PG, Grajales M. Internalized stigma of mental illness: Psychometric properties of a new measure. Psychiatry Res. 2003;121(1):31-49. [PMID: 14572622]

43. Ritsher JB, Phelan JC. Internalized stigma predicts erosion of morale among psychiatric outpatients. Psychiatry Res. 2004;129(3):257-65. [PMID: 15661319]

44. Reynolds WM. MAQ: Multidimensional Anxiety Questionnaire: Professional manual. Odessa (FL): Psychological Assessment Resources; 1999.

45. Haatainen KM, Tanskanen A, Kylmä J, Antikainen R, Hintikka J, Honkalampi K, Koivumaa-Honkanen H, Viinamäki $\mathrm{H}$. Life events are important in the course of hopelessness-A 2-year follow-up study in a general population. Soc Psychiatry Psychiatr Epidemiol. 2003;38(8):436-41. [PMID: 12910339]

46. McClain CS, Rosenfeld B, Breitbart W. Effects of spiritual well-being on end-of-life despair in terminally-ill cancer patients. Lancet. 2003;361(9369):1603-8. [PMID: 12747880]
47. Folkman S, Lazarus RS. Manual for the Ways of Coping Questionnaire. Palo Alto (CA): Consulting Psychologists Press; 1988.

48. Wineman NM, Durand EJ, McCulloch BJ. Examination of the factor structure of the Ways of Coping Questionnaire with clinical populations. Nurs Res. 1994;43(5):268-73. [PMID: 7937172]

49. Lysaker PH, Johnannesen JK, Lancaster RS, Davis LW, Zito $\mathrm{W}$, Bell MD. A rationally devised scoring scheme to assess coping in schizophrenia: Internal consistency and associations with work performance. Int J Psychosoc Rehabil. 2004;8:41-51.

50. Lysaker PH, Davis LW, Eckert GJ, Strasburger AM, Hunter NL, Buck KD. Changes in narrative structure and content in schizophrenia in long term individual psychotherapy: A single case study. Clin Psychol Psychother. 2005;12(5):406-16.

51. Roe D. Progressing from patienthood to personhood across the multidimensional outcomes in schizophrenia and related disorders. J Nerv Ment Dis. 2001;189(10):691-99.

[PMID: 11708670$]$

Submitted for publication July 19, 2007. Accepted in revised form January 22, 2008. 